\title{
Recycling-Oriented Design in Soft Robotics
}

\author{
Anh Minh Nguyen and Arthur Seibel * \\ Workgroup on System Technologies and Engineering Design Methodology, Hamburg University of Technology, \\ 21073 Hamburg, Germany \\ * Correspondence: arthur.seibel@tuhh.de
}

Received: 24 June 2019; Accepted: 6 August 2019; Published: 12 August 2019

\begin{abstract}
Soft robotics is a novel approach in the field of robotics. Soft robots or soft actuators are typically polymer-based and are characterized by their flexibility and adaptability, which brings new far-reaching applications. Soft robotics is currently at the peak of its research. One circumstance that is also present in this age is constant climate change; there is a demand for sustainability. This goes hand in hand with the design of products that are suitable for recycling. Today, more is expected of an engineer than just function-oriented design. This article looks at soft robotics from the point of view of sustainability. Since nature operates in cycles, the aim is to design products in such a way that they can be introduced into cycles. Three recycling cycles for products can be distinguished, which take place during production, during product use, and after product life. Within the framework of this work, special design measures are reviewed for fluidic elastomer actuators-a characteristic type of soft actuators-so that they can be integrated into the recycling process.
\end{abstract}

Keywords: soft robotics; recycling-oriented design; fluidic elastomer actuators (FEAs)

\section{Introduction}

When the term robotics is used, it typically refers to industrial robots or humanoid robots. These represent rigid robotics. Built up from rigid components in combination with joints, classical, hard robotics has developed greatly in the last 50 years and has become indispensable in today's industry [1]. However, a closer look at nature reveals that rigid elements are always coupled with soft tissue. This can be seen, for example, in skeletons with skin and muscles or in the paws of mammals [2,3]. The common feature of all is the flexibility and elasticity, which makes it possible to adapt to complex unstructured environments [4].

This characteristic is taken up in soft robotics. Using nature as a model [5], robots are designed according to the way animals move [6]. This includes, for example, worm-like [7] or fish-like robots [8]. Gripping with human hands [9,10], octopus arms [11], and grippers [12]—all based on compliant elements-also represents a large field of research.

Soft robotics is a relatively young field. As is usual for new areas of research, the main focus lies on progress. Research of new materials, actuation possibilities, sensor technology, and control systems are challenges in soft robotics, as they differ completely from the principles of rigid robotics [13]. In these diverse fields of research, the environmental aspect is moved far into the background or is not considered at all. With progressive climate change and the realization of limited resources, however, there is a strong need for sustainability.

The aim of this work is to investigate and discuss soft robotics with regard to recycling-oriented design, which should be regarded as a thought-provoking impulse. Since soft robotics is still in its infancy, the inclusion of sustainability at an early design stage can lead to simpler implementation in the future or can be steered in the right direction by certain approaches. For reasons of simplicity, we restrict ourselves exclusively to the recycling-oriented design of fluidic elastomer actuators (FEAs) as they are the most frequently used elements in soft robotics $[13,14]$. 


\section{Recycling Cycles}

As nature operates in cycles, products should be designed in such a way that they can be returned into cycles, as far as possible. A distinction can be made between three cycles $[15,16]$ : the primary cycle (pre-consumer recycling), the secondary cycle (recycling during product use or consumer recycling), and the tertiary cycle (post-consumer recycling).

The primary cycle refers to the production process and involves recycling of production waste, which can be returned to the cycle either directly, that is, without prior treatment (e.g., direct melting), or indirectly with pretreatment (e.g., cleaning prior to melting).

The secondary cycle takes place during product use. The aim is to preserve the product, which has a high value level in its current form, for as long as possible. After its initial use, the product is either to be reused directly (e.g., gas container) or reconditioned for further use (indirect recycling). A loss of value is obtained if the product is reused for a purpose other than its original use (e.g., tires as buffers for ships in a port).

The tertiary cycle deals with reconditioning of products after use. If a product cannot be reused or if a reuse is uneconomical, the individual materials must be extracted from the product for further processing. This may result in the same product again (if the materials used are fully recyclable) or, if undergoing the original production process is not possible, another use for the materials may be found (e.g., shredded tires as playground surfaces).

\section{Actions in the Primary Cycle}

In the primary cycle, the selected manufacturing processes are of importance. The aim is to select processes that do not produce any waste or as little waste as possible. In addition, manufacturing processes are optimal that make it possible to manufacture an entire assembly as one part, as products made of one material are the easiest to recycle.

The manufacturing processes of FEAs can basically be subdivided into casting processes [17] and additive manufacturing processes [18]. In the following, it is discussed to what extent these processes are suitable for the primary cycle.

\subsection{Casting Processes}

The components of an FEA-consisting of an elastomer body and a strain-limiting layer-are manufactured independently of each other in casting processes. They are later connected to each other to form the actuator. The preferred materials are various types of silicone rubber for the elastomer body $[19,20]$ and fiber-reinforced composites for the strain-limiting layer [21,22].

First, non-cross-linked liquid silicone rubber is mixed and poured into the corresponding mold. Excess liquid silicone rubber can accumulate when pouring into the molds, venting the silicone mixture, or manually adjusting the filling level to the mold. In the liquid state, the excess silicone rubber can be collected and used for the production of further actuators; a direct recovery can take place. After cross-linking under the influence of heat, the excess silicone rubber can no longer be melted and can therefore no longer be returned into the production process. It can only be disposed of. These residues should be collected together with already used actuators after product use. This procedure enables material utilization.

The molds and support parts used, such as the pins for retractable pin casting [17], become waste materials. Here, it is important to ensure that these parts are made of easily recyclable materials. As an additive manufacturing process, stereolithography has established itself for the production of molds. This process is based on the production of components by irradiation of light-active liquid resin, which can be classified as thermosetting plastic. Due to the non-meltability and insolubility of thermosets, the recycling process is more difficult. Energy recovery is preferred for thermosets, which is why their use should be avoided. Thermoplastic materials, on the other hand, are meltable and therefore easier to recycle. For this reason, they should rather be used for the production of casting 
molds. Other types of rapid prototyping processes such as selective laser sintering, fused deposition modeling, etc. [18] are available, which also work with thermoplastic materials. In addition to that, machines are obtainable which allow extruding filaments out of shredded wasted plastic used for the fused deposition modeling process. These include, for example, the "Filastruder" [23] or the "Protocycler" [24], where the latter also provides a built-in grinder for shredding own waste material. This means that used casting molds can be utilized to form new casting molds, enabling an in-house recycling cycle. However,thermoset molds can still be shredded and finely ground and then used, for example, as granulate for universal grippers $[25,26]$.

\subsection{Additive Production Processes}

Additive production processes can be divided into two basic principles. In some processes, a bath of base material is irradiated with light, from which a component is formed by chemical reaction. These include selective laser sintering with powder [27] and stereolithography with liquid resin [28,29]. The remaining powder or resin can be reused after filtering out unintentionally reacted particles. Direct recovery can thus take place.

The other methods create components by dispensing material through nozzles. These include fused deposition modeling [30], direct ink writing [31,32], and direct ink-jet printing [33]. There is no waste at all because the material is converted directly into the component. These methods are therefore ideally suited as manufacturing processes for FEAs.

\section{Actions in the Secondary Cycle}

The secondary cycle represents recycling of products without undergoing the original type of production process. This is achieved by keeping the product in operation for as long as possible and is defined as function-preserving recycling. The focus here lies on maintenance and repair. The end of life of an FEA occurs as soon as it bursts at some point or becomes leaky as a result of the internal pressure. Critical points are the chambers, which expand strongly, and the connection between the strain-limiting layer and the elastomer body.

\subsection{Material}

The first approach would be to close these leaking areas. The commonly used materials for FEAs are silicone rubbers. They belong to the class of elastomers and have the property of not being meltable. This means that already cross-linked or vulcanized silicone rubber cannot be cross-linked with other silicone rubber at a later point in time. Thus, patching the formed hole with an extra layer of silicone is not a solution to this problem as the closed area remains a weak point.

Ideally, the material should allow the holes to be closed again. Such a material called Diels-Alder polymer was presented by Terryn et al. [34] in combination with FEAs. It consist of thermoreversible covalent bonds and can close microscopic and macroscopic cracks by applying heat. Another approach would be to use stretchable composites consisting of elastomer and short reinforcing fibers that are resistant to puncture and that can self seal [35]. A recent perspective on self-healing soft materials is given in [36].

\subsection{Modularity}

When considering the structure of typical FEA applications, such as grippers [19] or four-legged soft robots [37], it can be seen that they are usually built of one coherent part. This has the advantage of simple and time-saving production. However, a major disadvantage arises as soon as the soft robot is no longer functional, for example, when a chamber bursts. Since soft robots based on silicone rubber cannot be repaired by closing the hole, they can no longer be used and must be disposed of as a whole. This results in a much shorter product life and thus higher environmental impact. A product must therefore be designed in such a way that units can be removed and repaired and parts replaced with new or regenerated ones; a modular design is required [38,39]. Applications of FEAs, 
such as four-legged robots or grippers, can be functionally divided into the limbs that perform the movements and the main body that holds the limbs. After that, a modularization should take place, so that if, for example, one part fails, it can be replaced and the soft robot can continue to be operated. Therefore, a separable connection must be created between the legs and the main body. According to Pahl et al. [40], separable connections can be subdivided into force and form connections.

\subsubsection{Force Connections}

Detachable connections include frictional connections. Their relative displacement is prevented as long as the force caused by static friction is not exceeded. This principle includes the pressing of components against each other and the use of force-inducing parts such as screws or clamps.

Morin et al. [41] showed an approach in soft robotics with pluggable elements, which are based on Lego bricks. The cuboid blocks have uniformly arranged cylinders on the upper side and counterparts in the form of cylindrical recesses on the lower side. The cylinders and recesses are inserted into each other and are held together by a frictional connection. In the horizontal direction, a form connection is also achieved (see next section). The bricks are available in various sizes and shapes, for example, as circular parts, and allow creating designs at will.

The blocks can also be used for pressurized designs. The bricks are arranged in such a way that a chamber is formed. To seal the structure, the bricks are glued together, where liquid silicone rubber is used as adhesive. Because of the possibility to create free components by assembling the bricks, it is also possible to build complete soft robots.

For the modularization of a soft robot, a press-fit connection can be used as a force connection, generated by an oversize fit. For this purpose, the designs of the main body and the legs of the robot are provided with elements that can be plugged into each other, similar to Lego-like building blocks. Figure 1 shows a CAD model. The main body is colored in blue and a leg in red. The design of the leg is provided with a hexagonal addition, and the main body has a cylinder with the negative. These are put into each other.

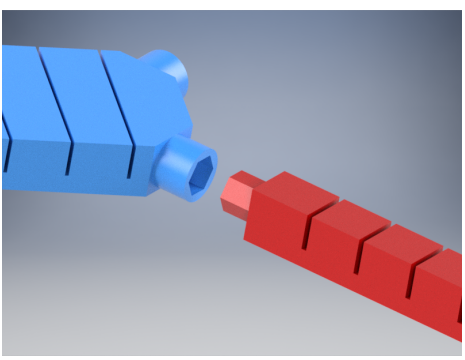

(a)

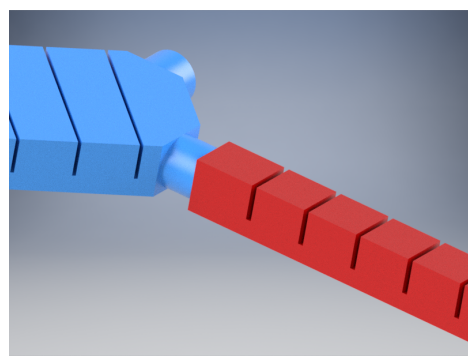

(b)

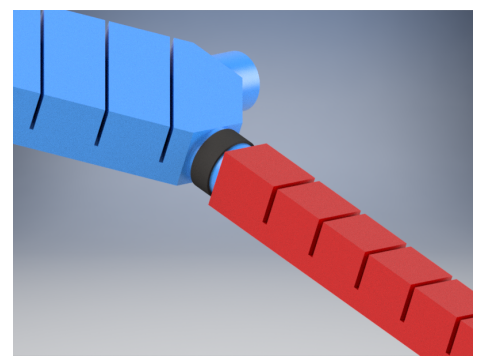

(c)

Figure 1. CAD model of a frictional connection: (a) unconnected; (b) connected; and (c) with additional elastic ring (blue: main body; red: leg).

Due to the flexibility of the materials of both elements, easy assembly and disassembly is possible by simply plugging and unplugging of the parts. However, this is also accompanied by a possible loosening during operation, especially if a force directly counteracts the static friction force, as is the case, for example, with gripper applications. To counteract this, a supporting part can be used which generates an additional clamping force and thus increases the normal force, as illustrated in Figure 1c with an additional elastic ring. An alternative to this is to use a magnetic assembly, as demonstrated in [42].

\subsubsection{Form Connections}

Form connections are created by the interlocking of at least two connecting partners. As a result, the connecting partners cannot come loose, without or with interrupted force transmission. 
Form connections are particularly suitable with regard to the recycling aspect since a detachable connection is provided and no extra parts are required.

One possibility to create a form connection is the use of dovetail joints [43]. It can be distinguished between single-taper and double-taper dovetails. With a single-taper dovetail shape, the angled shape prevents movement in the horizontal direction. Due to the flexible behavior of the soft polymer, more acute angles can be selected than with harder materials. This leads to an enlargement of the working surfaces. With harder materials, this would normally increase the risk for mechanical failure. In the double-taper version, the movement is additionally limited in the vertical direction, which is why this connection can only be realized with soft polymer. With harder materials, it would not be mountable. In the case of silicone rubber, the ends can be compressed and thus joined together.

Morin et al. [43] used this dovetail form for plates that were joined to form cubes. By gluing the joints together, such a cube can be sealed, so that it can withstand pressure. The cubes can then be placed on a strain-limiting layer, for example, by means of Lego adapters, to form an actuator. This actuator concept allows the replacement of individual cubes or chambers, which optimally fulfills the function-preserving recycling.

The dovetail connection can be adapted for connecting the main body and leg of existing robots, as shown in Figure 2. The dovetail connection limits the movement in horizontal direction by means of a form connection. In vertical direction, the friction force between the outer walls of the joint prevents movement. An oversize fit should be selected for this purpose. The flexibility of the silicone rubber enables assembly and disassembly. In some cases, the frictional connection may also have to be glued (see above).

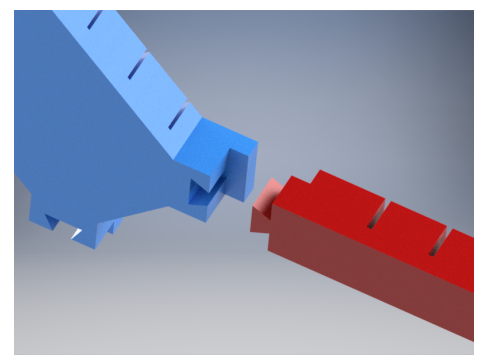

(a)

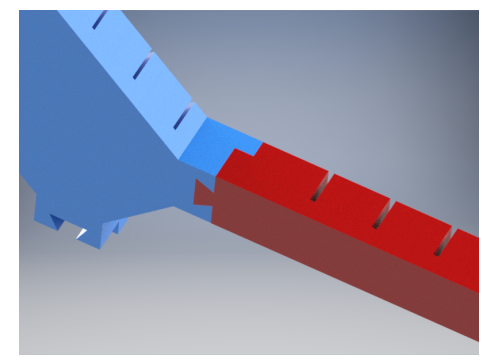

(b)

Figure 2. CAD model of a dovetail connection for FEAs: (a) unconnected; and (b) connected (blue: main body; red: leg).

\section{Actions in the Tertiary Cycle}

The tertiary cycle represents the recycling process after product life. The focus is on materials used in connection with the corresponding recyclability and the possibility of being able to separate the elements of the assembly from each other for a sorted disposal. Separability can be classified as design for disassembly.

\subsection{Material}

The aim here is to have as little material diversity as possible. Products consisting completely of one material are optimal since no disassembly is necessary and they are directly sorted. Composite materials, on the other hand, are difficult to separate and therefore hardly recyclable, which is why using them is not recommended.

\subsubsection{Elastomer Body}

Silicone rubbers are most commonly used for FEAs due to their elasticity and flexibility, which allow optimal actuation. However, they are difficult to recycle. Silicone rubbers are not meltable, as is typical for elastomers, and have to be ground into powder in order to be used as recyclate. However, 
selected companies are already providing raw material recycling by converting silicone powder into silicone oil [44,45]. Furthermore, silicone powder can be devulcanized by different techniques [46-48] and made reactive again.

Thermoplastics or thermoplastic elastomers are more suitable here. They are melted after coarse grinding and can thus flow back into new products. Therefore, they are easier to recycle. Even if the technical properties of thermoplastics are behind those of silicone rubbers so far, they should not be ignored as materials for FEAs in the future.

In connection with sustainability, biodegradable polymers should also be mentioned [49-53]. They are typically based on gelatin material, which shows similar mechanical properties as conventional silicone rubbers and can even be eaten after product use.

\subsubsection{Strain-Limiting Layer}

The strain-limiting layer has the task of limiting the linear extension of the actuator. A composite material can be used for this purpose, produced, for example, by embedding fibers [54], textiles [19,21,22], or paper [20] in a polymer matrix based on the same silicone rubber as the elastomer body. With sustainability in mind, this variant is not appropriate as the different materials must be separated for recycling.

Due to the circumstance that elastomers and thermosets are not solvable or meltable, a separation of fibers and matrix for a material recycling is only possible by particle recycling. For thermoset-based composites, this is achieved with a hammer mill. The matrix is milled into a fine powder and is sieved out, while the fibers remain as short fiber scraps. This approach is basically the same for tires with the difference that the soft rubber is initially embrittled by use of liquid nitrogen, which is known as cryomilling. An alternative to this process is ambient milling, which is carried out at room temperature. Tires undergo several stages of shredding and milling. During and between these stages, fibers are sieved out and are air separated.

These processes for tires can be applied to silicone composites. The difference in costs for recycling a silicone composite and a pure silicone component is noticeable as, besides a milling process, there is a need for either liquid nitrogen or a sieve system with multiple elements. For the sheer amount of tires, these costly processes are appropriate, while, for the low amount of silicone rubbers or silicone composites, this is not feasible. Thus, after disposal as a whole, only energy recovery is executed as of right now.

It is also common to use silicone rubber with a higher modulus of elasticity for the strain-limiting layer. PDMS, for example, is typically used for elastomer bodies made of Ecoflex [19,37]. The recycling possibility of an actuator consisting of different silicone rubbers depends on the recycling processes. In the case of feedstock recycling, it may be possible to recycle both materials together. In the case of material recycling by grinding, the decisive factor is whether the materials can be introduced into new products as mixed powder. So, in order to use a different material for the strain-limiting layer in recycling-oriented design, it is therefore necessary to know the exact recycling process. This can be accomplished, for example, by selecting appropriate recycling companies.

A clearly sustainable approach in this regard is to increase the thickness of the strain-limiting layer [19]. In this case, the entire actuator is made of one material, which is the best possible condition for recycling.

Furthermore, the connection between the strain-limiting layer and the elastomer body must be considered. In most cases, the liquid silicone rubber that the elastomer body and the strain-limiting layer are made from is used to bond the two parts together. This is also suitable with regard to recycling. Other adhesives would have to be removed beforehand to allow material recycling of the actuator. As this is a cumbersome process, an FEA would be energetically recovered under these circumstances. 


\subsection{Design for Disassembly}

In the event that it is not possible to avoid using components made of different materials, quick and easy disassembly should be ensured. This leads to a shorter disassembly time with correspondingly lower costs. It also means keeping the types and variety of connections to a minimum.

\subsubsection{Strain-Limiting Layer}

When considering different designs of FEAs, it can generally be stated that the strain-limiting layer is connected to the elastomer body in such a way that it is flush. On the outside, both appear as one continuous part. Although it is optically appealing, it makes it difficult to separate the layer from the elastomer body. Separation is possible with a certain amount of manual force, but this design is not suitable for disassembly.

One possibility is to let the strain-limiting layer protrude over the elastomer body. This creates a point of attack. Elastomer body and strain-limiting layer are produced independently of each other and then glued together. Accordingly, the glued surfaces create a weak spot. This area can be used to remove the strain-limiting layer from the elastomer body. For this purpose, the elastomer body is held in place and the strain-limiting layer is pulled vertically away from the elastomer body.

\subsubsection{Fiber-Reinforced FEAs}

An alternative approach to FEAs is the integration of fibers $[9,21]$. The goal of fiber integration is radial restriction so that the actuator can only expand in axial direction. The strain-limiting layer then converts this expansion into bending. The radially limiting material is also required to be able to follow the bending.

The problem is evident in the disposal. The fibers cannot be recycled together with the elastomer. They must be separated from the actuator. The fact that the fibers lie in grooves in the elastomer wall of the actuator makes the process even more tedious. Therefore, designs are to be found that consist of easily removable materials and are available in as few parts as possible.

As an alternative to fiber reinforcement, Miron et al. [55] developed an elastic sleeve that serves the same purpose as fibers but is more durable. Fiber-reinforced actuators have a short service life. The reason for this is the strong concentrated loads that the fibers exert on the actuator when hindering the radial expansion. A sleeve with a homogeneously distributed force prevents local loads and surface damage and allows operation below the fatigue limit.

This sleeve consists of two elements (see Figure 3). The first element is a braided elastic band made of special rubber, which is often used for clothing (Figure 3a). This band prevents radial expansion and is stretchable in axial direction. The second element is a strip of non-elastic nylon fabric that acts as a strain-limiting layer (Figure 3b). Both elements are sewn together (Figure 3c). A tube made of silicone (Figure 3d) is used as the pressurized element, which is closed at both ends with sealing caps, whereby one cap has an inlet for the pneumatics. The sleeve is pulled over the tube and fastened to the sealing caps with clamps (Figure 3e). Figure $3 \mathrm{f}$ shows the finished actuator in operation.

With regard to sustainability, this option can be assessed as recycling-oriented, as it is designed for disassembly. Only the clamps have to be opened to separate the cover from the silicone tube. This also works non-destructively, which makes it easy to dispose of and replace elements. The cover itself can be opened at the seams to separate the two bands. 


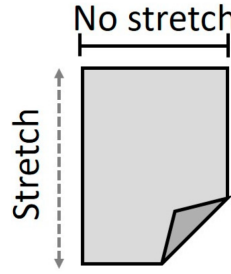

(a)

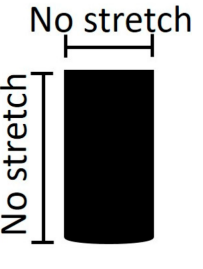

(b)

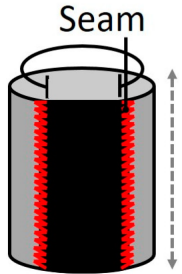

(c)

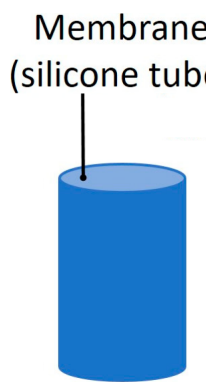

(d)

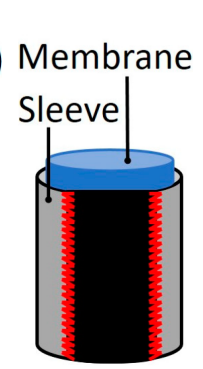

(e)

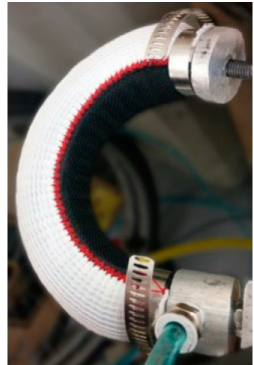

(f)

Figure 3. Structure of an actuator with an elastic sleeve [55]: (a) elastic band; (b) strain-limiting layer; (c) assembly of the sleeve; (d) silicone tube; (e) actuator assembly; and (f) actuator under pressure.

\section{Conclusions}

Silicone rubbers have proven to be the most successful material for fluidic elastomer actuators (FEAs) and are therefore most widely used. They are, however, difficult to recycle because they cannot be melted and must be ground into powder for material utilization. When mixed with other materials, they can only be used as fillers. For material recycling, appropriate companies must be contacted. This requires sorting of the materials by type.

After considering FEAs regarding their recycling-oriented design, it can be stated that, despite the silicone-rubber-based design of soft robots, recycling can be applied in every area of the product life cycle (production, product use, and disposal).

With regard to production, 3D printing processes are to be preferred to casting processes. Casting processes generate additional waste materials with the required casting molds. 3D printing processes produce the object without additional support objects, and in the case that silicone is used as material, 3D-printed actuators are in no way inferior to cast actuators [31].

With regard to product use, modularization by means of force or form connections is required, whereby form connections are more suitable since no additional parts are needed. This measure also ensures a longer product life.

With regard to disposal, particular attention must be paid to the materials used. The variety of materials should be kept as low as possible. FEAs offer the possibility of manufacturing a soft robot entirely from one material. Instead of selecting an additional material for the strain-limiting layer, an increase in stiffness can also be achieved by increasing the thickness.

Furthermore, design for disassembly is decisive as to whether a product can be truly recycled or just used to generate energy. For strain-limiting layers that use an additional material for stiffening, there are possibilities to separate them from the silicone. For fiber-reinforced actuators, which can only be disassembled with great effort, there are alternatives that are far more suitable for disassembly, such as the use of an elastic sleeve.

In future research, the rules shall be applied to more complicated elements, such as soft sensors [56], soft pumps [57,58], or soft electronics [59,60].

Author Contributions: Conceptualization, A.M.N. and A.S.; writing-original draft preparation, A.M.N. and A.S.; writing-review and editing, A.M.N. and A.S.; and supervision, A.S.

Funding: This research received no external funding.

Acknowledgments: The publication of this article was supported by the German Research Foundation (DFG) and Hamburg University of Technology (TUHH) in the funding programme "Open Access Publishing".

Conflicts of Interest: The authors declare no conflict of interest. 


\section{References}

1. Craig, J.J. Introduction to Robotics: Mechanics and Control; Pearson: Essex, UK, 2014.

2. Kim, S.; Laschi, C.; Trimmer, B. Soft robotics: A bioinspired evolution in robotics. Trends Biotechnol. 2013, 31, $287-294$. [CrossRef] [PubMed]

3. Laschi, C.; Cianchetti, M. Soft robotics: New perspectives for robot bodyware and control. Front. Bioeng. Biotechnol. 2014, 2, 3. [CrossRef] [PubMed]

4. Iida, F.; Laschi, C. Soft robotics: Challenges and perspectives. Procedia Comput. Sci. 2011, 7, 99-102. [CrossRef]

5. Whitesides, G.M. Bioinspiration: Something for everyone. Interface Focus 2015, 5, 20150031. [CrossRef] [PubMed]

6. Calisti, M.; Picardi, G.; Laschi, C. Fundamentals of soft robot locomotion. J. R. Soc. Interface 2017, 14, 20170101. [CrossRef] [PubMed]

7. Seok, S.; Onal, C.D.; Wood, R.; Rus, D.; Kim, S. Peristaltic locomotion with antagonistic actuators in soft robotics. In Proceedings of the IEEE International Conference on Robotics and Automation (ICRA), Anchorage, AK, USA, 3-8 May 2010; pp. 1228-1233.

8. Marchese, A.D.; Onal, C.D.; Rus, D. Autonomous soft robotic fish capable of escape maneuvers using fluidic elastomer actuators. Soft Robot. 2014, 1, 75-87. [CrossRef]

9. Deimel, R.; Brock, O. A novel type of compliant and underactuated robotic hand for dexterous grasping. Int. J. Robot. Res. 2016, 35, 161-185. [CrossRef]

10. Fras, J.; Althoefer, K. Soft biomimetic prosthetic hand: Design, manufacturing and preliminary examination. In Proceedings of the IEEE/RSJ International Conference on Intelligent Robots and Systems (IROS), Madrid, Spain, 1-5 October 2018; pp. 1-6.

11. Laschi, C.; Cianchetti, M.; Mazzolai, B.; Margheri, L.; Follador, M.; Dario, P. Soft robot arm inspired by the octopus. Adv. Robot. 2012, 26, 709-727. [CrossRef]

12. Shintake, J.; Cacucciolo, V.; Floreano, D.; Shea, H. Soft robotic grippers. Adv. Mater. 2018, 30, 1707035. [CrossRef]

13. Rus, D.; Tolley, M.T. Design, fabrication and control of soft robots. Nature 2015, 521, 467-475. [CrossRef]

14. Polygerinos, P.; Correll, N.; Morin, S.A.; Mosadegh, B.; Onal, C.D.; Petersen, K.; Cianchetti, M.; Tolley, M.T.; Shepherd, R.F. Soft robotics: Review of fluid-driven intrinsically soft devices; manufacturing, sensing, control, and applications in human-robot interaction. Adv. Eng. Mater. 2017, 19, 1700016. [CrossRef]

15. Jorden, W. Recycling Conform Design. In Materials Substitution and Recycling. AGARD Conference Proceedings No. 356; AGARD: Neuilly sur Seine, France, 1984; p. 23.

16. Jorden, W. Designing of products in view of recycling. In Environmental Technology; Martinus Nijhoff Publishers: Dordrecht, The Netherlands, 1987; pp. 367-376.

17. Marchese, A.D.; Katzschmann, R.K.; Rus, D. A recipe for soft fluidic elastomer robots. Soft Robot. 2015, 2, 7-25. [CrossRef]

18. Wallin, T.J.; Pikul, J.; Shepherd, R.F. 3D printing of soft robotic systems. Nat. Rev. Mater. 2018, 3, 84-100. [CrossRef]

19. Ilievski, F.; Mazzeo, A.D.; Shepherd, R.F.; Chen, X.; Whitesides, G.M. Soft robotics for chemists. Angew. Chem. Int. Ed. 2011, 50, 1890-1895. [CrossRef]

20. Mosadegh, B.; Polygerinos, P.; Keplinger, C.; Wennstedt, S.; Shepherd, R.F.; Gupta, U.; Shim, J.; Bertoldi, K.; Walsh, C.J.; Whitesides, G.M. Pneumatic networks for soft robotics that actuate rapidly. Adv. Funct. Mater. 2014, 24, 2163-2170. [CrossRef]

21. Galloway, K.C.; Polygerinos, P.; Walsh, C.J.; Wood, R.J. Mechanically programmable bend radius for fiber-reinforced soft actuators. In Proceedings of the International Conference on Advanced Robotics (ICAR), Montevideo, Uruguay, 25-29 November 2013.

22. Tolley, M.T.; Shepherd, R.F.; Mosadegh, B.; Galloway, K.C.; Wehner, M.; Karpelson, M.; Wood, R.J.; Whitesides, G.M. A resilient, untethered soft robot. Soft Robot. 2014, 1, 213-223. [CrossRef]

23. Filastruder. Available online: https://www.filastruder.com/collections/filastruders-accessories/products / filastruder-kit (accessed on 10 August 2019).

24. Protocycler. Available online: https://redetec.com/pages/protocycler (accessed on 10 August 2019). 
25. Brown, E.; Rodenberg, N.; Amend, J.; Mozeika, A.; Steltz, E.; Zakin, M.R.; Lipson, H.; Jaeger, H.M. Universal robotic gripper based on the jamming of granular material. Proc. Natl. Acad. Sci. USA 2010, 107, 18809-18814. [CrossRef]

26. Amend, J.R.; Brown, E.; Rodenberg, N.; Jaeger, H.M.; Lipson, H. A positive pressure universal gripper based on the jamming of granular material. IEEE Trans. Robot. 2012, 28, 341-350. [CrossRef]

27. Scharff, R.B.N.; Doubrovski, E.L.; Poelman, W.A.; Jonker, P.P.; Wang, C.C.L.; Geraedts, J.M.P. Towards behavior design of a 3D-printed soft robotic hand. In Soft Robotics: Trends, Applications and Challenges; Springer: Cham, Switzerland, 2017; pp. 23-29.

28. Peele, B.N.; Wallin, T.J.; Zhao, H.; Shepherd, R.F. 3D printing antagonistic systems of artificial muscle using projection stereolithography. Bioinspir. Biomim. 2015, 10, 055003. [CrossRef]

29. Patel, D.K.; Sakhaei, A.H.; Layani, M.; Zhang, B.; Ge, Q.; Magdassi, S. Highly stretchable and UV curable elastomers for digital light processing based 3D printing. Adv. Mater. 2017, 29, 1606000. [CrossRef]

30. Yap, H.K.; Ng, H.Y.; Yeow, C.H. High-force soft printable pneumatics for soft robotic applications. Soft Robot. 2016, 3, 144-158. [CrossRef]

31. Yirmibesoglu, O.D.; Morrow, J.; Walker, S.; Gosrich, W.; Canizares, R.; Kim, H.; Daalkhaijav, U.; Fleming, C.; Branyan, C.; Menguc, Y. Direct 3D printing of silicone elastomer soft robots and their performance comparison with molded counterparts. In Proceedings of the IEEE International Conference on Soft Robotics (RoboSoft), Livorno, Italy, 24-28 April 2018.

32. Byrne, O.; Coulter, F.; Glynn, M.; Jones, J.F.X.; Annaidh, A.N.; O'Cearbhaill, E.D.; Holland, D.P. Additive manufacture of composite soft pneumatic actuators. Soft Robot. 2018, 5, 726-736. [CrossRef]

33. Drotman, D.; Jadhav, S.; Karimi, M.; Dezonia, P.; Tolley, M.T. 3D printed soft actuators for a legged robot capable of navigating unstructured terrain. In Proceeding of the IEEE International Conference on Robotics and Automation (ICRA), Singapore, 29 May-3 June 2017; pp. 5532-5538.

34. Terryn, S.; Brancart, J.; Lefeber, D.; van Assche, G.; Vanderborght, B. Self-healing soft pneumatic robots. Sci. Robot. 2017, 2, eaan4268. [CrossRef]

35. Shepherd, R.F.; Stokes, A.A.; Nunes, R.M.D.; Whitesides, G.M. Soft machines that are resistant to puncture and that self seal. Adv. Mater. 2013, 25, 6709-6713. [CrossRef]

36. Bartlett, N.D.; Dickey, M.D.; Majidi, C. Self-healing materials for soft-matter machines and electronics. NPG Asia Mater. 2019, 11, 21. [CrossRef]

37. Shepherd, R.F.; Ilievski, F.; Choi, W.; Morin, S.A.; Stokes, A.A.; Mazzeo, A.D.; Chen, X.; Wang, M.; Whitesides, G.M. Multigait soft robot. Proc. Natl. Acad. Sci. USA 2011, 108, 20400-20403. [CrossRef]

38. Onal, C.D.; Rus, D. A modular approach to soft robots. In Proceedings of the IEEE RAS/EMBS International Conference on Biomedical Robotics and Biomechatronics (BioRob), Rome, Italy, 24-27 June 2012; pp. 1038-1045.

39. Seibel, A.; Schiller, L. Systematic engineering design helps creating new soft machines. Robot. Biomim. 2018, 5, 5. [CrossRef]

40. Pahl, G.; Beitz, W.; Feldhusen, J.; Grote, K.H. Engineering Design. A Systematic Approach, 3rd ed.; Springer: London, UK, 2007.

41. Morin, S.A.; Shevchenko, Y.; Lessing, J.; Kwok, S.W.; Shepherd, R.F.; Stokes, A.A.; Whitesides, G.M. Using 'click-e-bricks' to make 3D elastomeric structures. Adv. Mater. 2014, 26, 5991-5999. [CrossRef]

42. Kwok, S.W.; Morin, S.A.; Mosadegh, B.; So, J.H.; Shepherd, R.F.; Martinez, R.V.; Smith, B.; Simeone, F.C.; Stokes, A.A.; Whitesides, G.M. Magnetic assembly of soft robots with hard components. Adv. Funct. Mater. 2014, 24, 2180-2187. [CrossRef]

43. Morin, S.A.; Kwok, S.W.; Lessing, J.; Ting, J.; Shepherd, R.F.; Stokes, A.A.; Whitesides, G.M. Elastomeric tiles for the fabrication of inflatable structures. Adv. Funct. Mater. 2014, 24, 5541-5549. [CrossRef]

44. ECO U.S.A. Available online: https:// siliconerecycling.com (accessed on 10 August 2019).

45. N.C. Siamenergy Co., Ltd. Available online: http://www.nc-silicone.com (accessed on 10 August 2019).

46. De, D.; Das, A.; De, D.; Dey, B.; Debnath, S.C.; Roy, B.C. Reclaiming of ground rubber tire (GRT) by a novel reclaiming agent. Eur. Polym. J. 2006, 42, 917-927. [CrossRef]

47. Sombatsompop, N.; Kumnuantip, C. Comparison of physical and mechanical properties of NR/carbon black/reclaimed rubber blends vulcanized by conventional thermal and microwave irradiation methods. J. Appl. Polym. Sci. 2006, 100, 5039-5048. [CrossRef] 
48. Sun, X.; Isayev, A.I. Ultrasound devulcanization: Comparison of synthetic isoprene and natural rubbers. J. Mater. Sci. 2007, 42, 7520-7529. [CrossRef]

49. Chambers, L.D.; Winfield, J.; Ieropoulos, I.; Rossiter, J. Biodegradable and edible gelatine actuators for use as artificial muscles. In Proceedings of the SPIE Conference on Electroactive Polymer Actuators and Devices (EAPAD), San Diego, CA, USA, 9-13 March 2014.

50. Rossiter, J.; Winfield, J.; Ieropoulos, I. Here today, gone tomorrow: Biodegradable soft robots. In Proceedings of the SPIE Conference on Electroactive Polymer Actuators and Devices (EAPAD), Las Vegas, NV, USA, 20-24 March 2016.

51. Shintake, J.; Sonar, H.; Piskarev, E.; Paik, J.; Floreano, D. Soft pneumatic gelatin actuator for edible robotics. In Proceedings of the IEEE/RSJ International Conference on Intelligent Robots and Systems (IROS), Vancouver, BC, Canada, 24-28 September 2017; pp. 6221-6226.

52. Zolfagharian, A.; Kaynak, A.; Khoo, S.Y.; Kouzani, A.Z. Polyelectrolyte soft actuators: 3D printed chitosan and cast gelatin. 3D Print. Addit. Manuf. 2018, 5, 138-150. [CrossRef]

53. Zolfagharian, A.; Kouzani, A.Z.; Maheepala, M.; Khoo, S.Y.; Kaynak, A. Bending control of a 3D printed polyelectrolyte soft actuator with uncertain model. Sens. Actuators A Phys. 2019, 288, 134-143. [CrossRef]

54. Stalin, T.; Thanigaivel, N.K.; Joseph, V.S.; Valdivia y Alvarado, P. Automated fiber embedding for tailoring mechanical and functional properties of soft robot components. In Proceeding of the IEEE International Conference on Soft Robotics (RoboSoft), Seoul, Korea, 14-18 April 2019; pp. 762-767.

55. Miron, G.; Bédard, B.; Plante, J.S. Sleeved bending actuators for soft grippers: A durable solution for high force-to-weight applications. Actuators 2018, 7, 40. [CrossRef]

56. Li, S.; Zhao, H.; Shepherd, R.F. Flexible and stretchable sensors for fluidic elastomer actuated soft robots. MRS Bull. 2017, 42, 138-142. [CrossRef]

57. Wehner, M.; Tolley, M.T.; Mengüç, Y.; Park, Y.L.; Mozeika, A.; Ding, Y.; Onal, C.; Shepherd, R.F.; Whitesides, G.M.; Wood, R.J. Pneumatic energy sources for autonomous and wearable soft robotics. Soft Robot. 2014, 1, $263-274$. [CrossRef]

58. Adami, M.; Seibel, A. On-board pneumatic pressure generation methods for soft robotics applications. Actuators 2019, 8, 2. [CrossRef]

59. Rogers, J.A.; Someya, T.; Huang, Y. Materials and mechanics for stretchable electronics. Science 2010, 327, $1603-1607$. [CrossRef]

60. Lu, N.; Kim, D.H. Flexible and stretchable electronics paving the way for soft robotics. Soft Robot. 2014, 1, 53-62. [CrossRef] 